\title{
Potential- and Rate-Determining Step for Oxygen Reduction on Pt(111)
}

\author{
Tripkovic, Vladimir; Vegge, Tejs
}

Published in:

Journal of Physical Chemistry C

Link to article, DOI:

10.1021/acs.jpcc.7b07472

Publication date:

2017

Document Version

Peer reviewed version

Link back to DTU Orbit

Citation $(A P A)$ :

Tripkovic, V., \& Vegge, T. (2017). Potential- and Rate-Determining Step for Oxygen Reduction on Pt(111). Journal of Physical Chemistry C, 121(48), 26785-26793. https://doi.org/10.1021/acs.jpcc.7b07472

\section{General rights}

Copyright and moral rights for the publications made accessible in the public portal are retained by the authors and/or other copyright owners and it is a condition of accessing publications that users recognise and abide by the legal requirements associated with these rights.

- Users may download and print one copy of any publication from the public portal for the purpose of private study or research.

- You may not further distribute the material or use it for any profit-making activity or commercial gain

- You may freely distribute the URL identifying the publication in the public portal

If you believe that this document breaches copyright please contact us providing details, and we will remove access to the work immediately and investigate your claim. 


\title{
Potential and Rate Determining Step for Oxygen Reduction on $\operatorname{Pt}(111)$
}

\author{
Vladimir Tripkovic ${ }^{1^{*}}$, Tejs Vegge ${ }^{1}$ \\ ${ }^{1}$ Department of Energy Conversion and Storage, Technical University of Denmark, DK-2800 \\ Kgs. Lyngby, Denmark.
}

Abstract: Using density functional theory calculations, we study reaction thermodynamics and kinetics for the oxygen reduction reaction (ORR) on surface coverages that develop in the $0-1.0$ $V$ potential range on Pt(111), with special emphasis on the role of water. At low potentials, water affects adsorption energies of hydrophilic ${ }^{*} \mathrm{O}_{2}$ and ${ }^{*} \mathrm{OOH}$ intermediates but displays a limited effect on the transition state energies for their dissociation. We calculate the $\mathrm{O}_{2}$ and $\mathrm{OOH}$ adsorption and dissociation free energies at most stable surfaces in the investigated potential range and arrive at two important conclusions 1) the ORR proceeds through the associative reaction mechanism in the diffusion and the mixed kinetic-diffusion region and 2) moderate $\mathrm{O}_{2}$ and $\mathrm{OOH}$ activation energies support the notion that the reaction is predominantly controlled by the rate prefactor. We associate the rate prefactor with the probability for an $\mathrm{O}_{2}$ molecule to replace a water molelecule on hydrophilic $\left(\mathrm{OH}-\mathrm{H}_{2} \mathrm{O}\right.$ covered $)$ surfaces, and the inability of $\mathrm{O}_{2}$ to adsorb and dissociate on hydrophobic (O covered) surfaces that develop at higher potentials. Finally, in light of new results, we discuss activities of Pt alloys that lie close to the top of the volcano.

*corresponding author: vltr@dtu.dk

\section{Introduction}

Supporting a growing energy demand without increasing the carbon footprint requires development of new technologies based on renewable resources. The proton exchange membrane fuel cell (PEMFC) is an ideal example of a device that can satisfy society's energy needs and alleviate the anthropogenic impact on nature. The main fundamental problem that prevents PEMFCs from 'seizing the market' is the slow rate of oxygen reduction reaction (ORR) combined with the high cost of the platinum-based catalysts. Although platinum is the best elemental catalyst for the reaction, it is far from being ideal. The cost of platinum accounts for roughly $40 \%$ of the overall PEMFC costs assessed on a production scale of 500000 units per year. ${ }^{1}$ New strategies to improve the performance, electrochemical stability and activity of the fuel cell cathodes are currently being pursued. These include mixing platinum with other noble and non- 
noble metal constituents, ${ }^{2-13}$ tailoring the size, shape and interatomic distances of platinum and Ptalloy nanoparticles, ${ }^{14-22}$ making non-supported nanostructured catalysts ${ }^{23-27}$ and completely eliminating platinum, e.g. by using metal functionalized carbon templates. ${ }^{28-30}$

The search for new catalyst materials has largely been motivated by chemical intuition, empirical knowledge, but nowadays also inputs from computational studies. Density Functional Theory (DFT) calculations, in particular, have proved to be an invaluable complement in driving design of new catalysts. Simple guidelines established using DFT calculations have helped to identify several electro-catalytically active materials for the ORR. ${ }^{6,11,12}$ Most DFT studies to date have shown that ORR on the Pt-based catalysts proceeds through an associative path, where the first proton transfer step precedes the cleavage of the O-O bond. .,31-33 $^{-3}$

The ORR activity can be inferred from an activity-estimation plot, commonly known as a volcano plot. In the conventional picture, the ORR volcano is delimited by two potential determining steps; the ${ }^{1 *} \mathrm{OH}$ reduction to water, which defines the left and the $\mathrm{O}_{2}$ reduction to *OOH which defines the right leg of the volcano. ${ }^{34,35}$ The best catalysts are found at the intercept of the two respective legs. Pt is the best elemental catalyst for the ORR. It lies at the left volcano leg close to the volcano top. ${ }^{7,34}$ This position indicates that the reduction of $\mathrm{OH}$ to $\mathrm{H}_{2} \mathrm{O}$ is a Potential Determining Step (PDS) on $\mathrm{Pt}(111)$ and that it is slightly less exergonic at $\mathrm{U}=0 \mathrm{~V}$ than $\mathrm{O}_{2}$ reduction to $\mathrm{OOH}$. The potential scale throughout the text is given against the Reversible Hydrogen Electrode (RHE).

The volcano model is based solely on reaction thermochemistry, and its ability to capture activity trends stipulates that reaction kinetics are of much less importance, although there have been some recent attempts to explain the catalytic activity using a kinetic volcano. ${ }^{36,37}$ Kinetic barriers can come from proton transfer to the surface, i.e. proton discharge, proton diffusion in bulk water and/or on the surface, or cleavage of the $\mathrm{O}_{2}$ bond. It has previously been shown that proton diffusion barriers in bulk water and on the surface are rather small, usually on the order of $0.05-0.15 \mathrm{eV} \cdot{ }^{32,38-40}$ The proton discharge barriers are more difficult to quantify because they are dependent on the potential, $\mathrm{pH}$ and the catalyst morphology. ${ }^{41}$ DFT studies are usually restricted to calculating adsorption energies on bare surfaces in vacuum and then adding a posteriori the electrochemical environment by shifting the chemical potentials of protons and electrons, adding electric field and solvation corrections. ${ }^{34,42,43}$ Attempts to explicitly include and tune the potential

\footnotetext{
${ }^{1}$ Asterisk $(*)$ denotes an adsorbed species
} 
within the simulated cell have proven extremely challenging. ${ }^{41,44-47}$ A few studies that were able to extract proton discharge barriers have shown these to be around $0.2-0.25 \mathrm{eV}$ at $0.8 \mathrm{~V} .^{31,32}$ This is a very small barrier that cannot explain kinetic limitations observed in experiments. Excluding proton discharge and diffusion barriers indicates that the cleavage of the O-O bond is likely the Rate Determining Step (RDS). The dissociation barriers for breaking the O-O bond in different ORR intermediates $\left(\mathrm{O}_{2}, \mathrm{OOH}, \mathrm{HOOH}\right)$ have been computed in the past for different transition metals and their alloys. ${ }^{32,48-52}$ These studies have been limited to bare metal surfaces or in the best case to a fixed oxygenated species coverage. Herein, we calculate the ${ }^{*} \mathrm{O}_{2}$ and ${ }^{*} \mathrm{OOH}$ dissociation barriers under different coverages of oxygenated species that develop in the $0-1.0 \mathrm{~V}$ potential range.

The paper is structured as follows: first, we calculate stability ranges of different species and coverages in the $0-1.0 \mathrm{~V}$ potential window. We then elucidate the influence of water on the reaction energetics in the low potential limit, where the reaction is under diffusion control. Afterwards, we calculate the $\mathrm{O}_{2}$ and $\mathrm{OOH}$ adsorption and dissociation energies at the most stable coverages that develop in the $0-1.0 \mathrm{~V}$ range. Based on presented results, we derive an in-depth understading of the RDS and PDS on Pt(111), and explain why a mean-field approach based solely on the reaction thermochemistry gives satisfactory activity predictions for metals at the left volcano leg.

\section{Computational methods}

Total energies are calculated using Density Functional Theory (DFT) calculations employing the grid-based projector-augmented wave method (GPAW) code $^{53}$ integrated with Atomic Simulation Environment (ASE). Calculations are performed using the RPBE exchange-correlation functional ${ }^{54}$ and a grid spacing of 0.15 and $0.18 \AA$. Occupation of one-electron states is calculated at an electronic temperature of $\mathrm{k}_{\mathrm{B}} \mathrm{T}=0.1 \mathrm{eV}$, with the energies extrapolated to $\mathrm{T}=0 \mathrm{~K}$. The convergence is reached when the sum of absolute forces acting on atoms becomes less than 0.05 $\mathrm{eV \AA} \AA^{-1}$.

Pt electrodes are represented by periodically repeated slabs separated by $12 \AA$ vacuum. Five unit cell sizes with $2 \times 2,2 \times 4,3 \times 2,3 \times 3$ and $3 \times 4$ atoms in the surface layer are used to simulate the $\operatorname{Pt}(111)$ surface. These unit cells are sampled by the $4 \times 4 \times 1,3 \times 4 \times 1,4 \times 2 \times 1,4 \times 4 \times 1$ and $4 \times 3 \times 1$ Monkhorst-Pack k-point grids, ${ }^{55}$ respectively, which were found to be adequate for ensuring 
convergence of the total energy. For making a charge vs. potential plot, we use a slab thickness of 5 layers and a grid spacing of $0.15 \AA$. The two bottom layers are kept fixed, while the remaining atoms and adsorbates are allowed to relax. For calculating dissociation paths we used a smaller slab thickness of 3 layers ( 2 fixed) and a more coarse grid spacing of $0.18 \AA$. The adsorbates are allowed to relax together with the surface Pt layer. The transition states energies are calculated using a combination of a constrained bond length approach and Nudged Elastic Band (NEB) calculations in the following way: first, we constrain the distances between the $\mathrm{O}$ atoms in ${ }^{*} \mathrm{O}_{2}$ and * $\mathrm{OOH}$ intermediates and optimize an initial set of images that we then fed to NEB calculations. The images are relaxed with the NEB method until the sum of the forces on all the images in the chain is approximately $0.10 \mathrm{eV}^{-1}$. For such a preconverged chain of images, we make a final climbing image calculation to get the precise energy of the transition state.

The binding free energies of ${ }^{*} \mathrm{OOH}$ and ${ }^{*} \mathrm{O}_{2}$ on the bare and oxygen covered $\mathrm{Pt}(111)$ surface are calculated using Eq. (1)

$$
\Delta G_{O_{2} / O O H}=E\left(P t_{111}+\frac{n}{N} O+O_{2} / O O H\right)-E\left(P t_{111}+\frac{n}{N} O\right)-2 E\left(H_{2} O^{l}\right)+z E\left(H_{2}^{g}\right)+
$$

$\mathrm{ZPE}-\mathrm{T} \Delta \mathrm{S}$

, where $E\left(\mathrm{H}_{2} \mathrm{O}^{l}\right)$ is the energy of a liquid water molecule calculated using the room temperature gas-liquid equilibrium and $E\left(H_{2}^{g}\right)$ is the energy of hydrogen in the gas phase. ${ }^{34}$ The sum of the zero-point energy and entropy contributions for ${ }^{*} \mathrm{O}_{2}$ and ${ }^{*} \mathrm{OOH}$ are 0.1 and $0.4 \mathrm{eV}$, respectively. ${ }^{34}$ Expressions for calculating the binding free energies of ${ }^{*} \mathrm{OH}$ and ${ }^{*} \mathrm{OOH}$ in a half-dissociated water layer (HDWL), $\Delta G_{O H}^{H D W L}$ and $\Delta G_{O O H}^{H D W L}$, respectively are somewhat more complicated because one has to subtract co-adsorbed water:

$\Delta G_{O H}^{H D W L}=E\left(P t_{111}+\frac{n}{N} O H+\frac{n}{N} H_{2} O\right)-E_{P t_{111}}-\frac{n}{N} \Delta E_{H_{2} O}^{\text {bilayer }}-\frac{n}{N} E\left(H_{2} O^{l}\right)+\frac{n}{2 N} E\left(H_{2}^{g}\right)+0.35$

$\Delta G_{O O H}^{H D W L}=\Delta G_{O H}^{H D W L}+\mathrm{E}\left(P t_{111}+\frac{n-1}{N} O H+\frac{1}{N} O O H+\frac{n}{N} H_{2} O\right)-E\left(P t_{111}+\frac{n}{N} O H+\frac{n}{N} H_{2} O\right)$

$-E\left(H_{2} O^{l}\right)+\frac{n}{N} E\left(H_{2}^{g}\right)+0.05$

where $\frac{n}{N}=0.33 ; \mathrm{n}$ is the number of co-adsorbed $\mathrm{H}_{2} \mathrm{O}$ molecules, $N$ is the total number of surface atoms, $E_{P t_{111}}$ is the energy of a $\mathrm{Pt}(111)$ slab and 0.35 and $0.05 \mathrm{eV}$ are the sums of the zero-point energy and entropy corrections for $\mathrm{OH}$ in reaction (2) and $\mathrm{O}(\mathrm{OOH}-\mathrm{OH})$ in reaction (3), 
respectively. ${ }^{34}$ In deriving the expressions in Eq. (2) and (3), we make a commonly assumed conjecture that water at the surface is in equilibrium with water at the interface. ${ }^{37,52,56}$ It still not clear how water organizes at the surface under reaction conditions. As a representative water structure, we take water bilayer observed in UHV experiments, ${ }^{57}$ and used extensively in other computational studies to model metal/aqueous interfaces. ${ }^{41,52,58-62}$ The average and binding energy of a water molecule in the bilayer, $\Delta E_{\mathrm{H}_{2} \mathrm{O}}^{\text {bilayer }}$, is calculated as

$\Delta E_{H_{2} O}^{\text {bilayer }}=\frac{E\left(P t_{111}+\frac{n}{N} H_{2} O\right)-E_{P t_{111}}}{\frac{n}{N}}$.

The differential binding energy of water in the HDWL is given by the expression

$\Delta G_{H_{2} O}^{H D W L}=E\left(P t_{111}+\frac{n}{N} O H+\frac{n}{N} H_{2} O\right)-\left(P t_{111}+\frac{n}{N} O H+\frac{n-1}{N} H_{2} O\right)-\Delta E_{H_{2} O}^{\text {bilayer }}$

Free energy diagrams are constructed by shifting the chemical potential of electrons in reactions:

$$
\begin{gathered}
\mathrm{O}_{2}+4 \mathrm{H}^{+}+4 \mathrm{e}^{-} \rightarrow 2 \mathrm{H}_{2} \mathrm{O} \\
\mathrm{OOH}+3 \mathrm{H}^{+}+3 \mathrm{e}^{-} \rightarrow 2 \mathrm{H}_{2} \mathrm{O},
\end{gathered}
$$

by $\mu_{e^{-}}=-n e U$, where $U$ is the potential and $n$ the number of electrons, using the Computational Hydrogen Electrode approach. ${ }^{34}$

\section{Results and Discussion}

\section{Surface coverage}

Surface coverages are experimentally determined through charge-versus-potential plots in which the amount of transferred charge is directly proportional to the surface coverage. ${ }^{63}$ The computational charge-versus-potential plot is presented in Figure $1{ }^{34}$ As seen, in the $0-1.2 \mathrm{~V}$ potential range, the $\mathrm{Pt}(111)$ surface goes through four different oxidation states: a non-oxidized state, i.e. the bare $\mathrm{Pt}(111)$ surface from $0-0.73 \mathrm{~V}$ and three oxidized states in which the surface $\mathrm{O}$ coverage increases with potential. We find that a HDWL, ${ }^{60,64,65}$ with $0.33 \mathrm{ML} \mathrm{OH}$ is marginally less stable $(0.04 \mathrm{eV})$ than the $0.25 \mathrm{ML} \mathrm{O}$, indicating that the former adlayer does not form on $\operatorname{Pt}(111)$. However, the HDWL has been observed experimentally in UHV studies on $\operatorname{Pt}(111)^{57}$ and hypothesized to be responsible for a sharp feature at the end of a 'butterfly' peak in cyclic voltammograms on $\mathrm{Pt}(111){ }^{66}$ Furthermore, a simple kinetic model based on reaction 
thermochemistry has shown that completion of the HDWL inhibits the ORR activity. ${ }^{67}$ The reason why this structure is not found to be the energetically favored adlayer is probably due to an underestimation of the $\mathrm{OH}$ adsorption energy on $\mathrm{Pt}(111)$ at the DFT-RPBE/PBE level, ${ }^{68}$ and neglection of van der Waals (vdW) interactions, which were found to be $0.15 \mathrm{eV}$. ${ }^{6}$ Including vdW interactions would make the HDWL more stable than oxygen covered surfaces in the intermediate potential region. It should be noted that water does not exclusively form hexagons on the $\operatorname{Pt}(111)$ surface, there might be a range of different structures including pentagons, hexagons and heptagons present simultaneously. ${ }^{70,71}$ Furthermore, it was shown in a recent study that $\mathrm{OH}$ and $\mathrm{H}_{2} \mathrm{O}$ can form adsorption patterns other than that in HDWL. ${ }^{72,73}$ In fact, there is probably a large ensemble of energetically similar structures at the given coverage. Nevertheless, we take the HDWL as a representative water model because regardless of the exact $\mathrm{OH}-\mathrm{H}_{2} \mathrm{O}$ configuration, water will be locked at or near the surface owing to strong $\mathrm{OH}-\mathrm{H}_{2} \mathrm{O}$ bonds. ${ }^{73,74}$ Experimentally, the reaction inhibition occurs concomitantly with the development of the $0.44 \mathrm{ML}$ coverage. ${ }^{66}$ This specific coverage corresponds either to a higher $\mathrm{OH}$ coverage $\mathrm{F}^{72}$ or a mixed $\mathrm{O}$ and $\mathrm{OH}$ phase that is computationally not found to be stable, however the mixed $\mathrm{OH}$ and $\mathrm{O}$ adlayer might form a long range order (a super structure) that cannot be captured by a relatively small size of the simulated cell. 


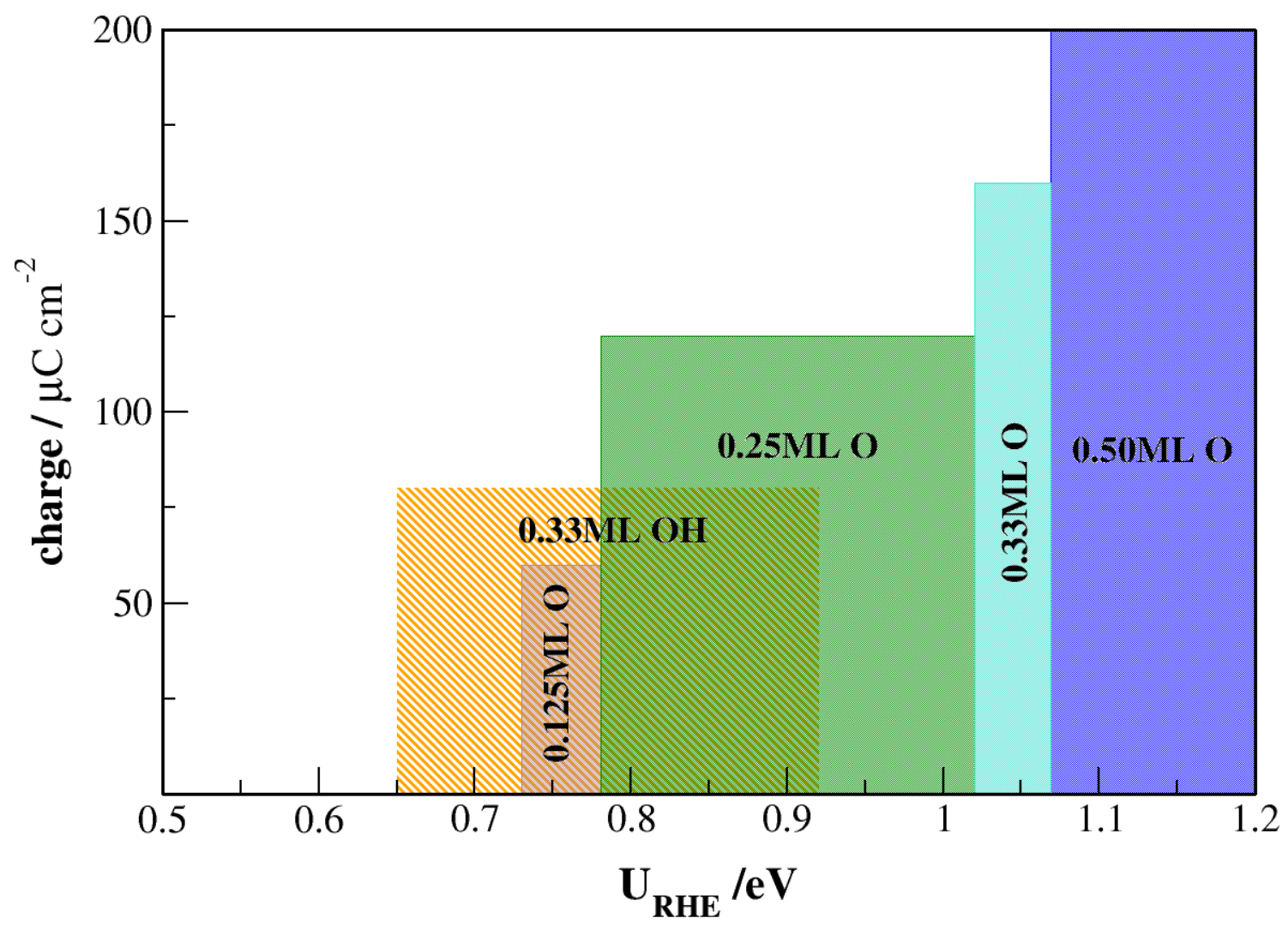

a)

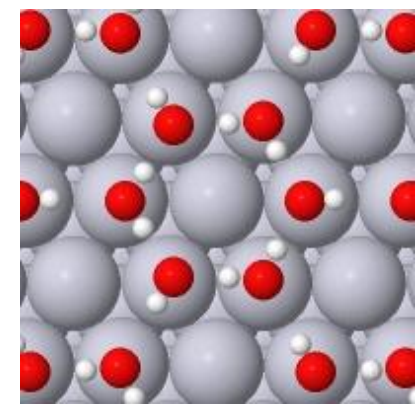

b)

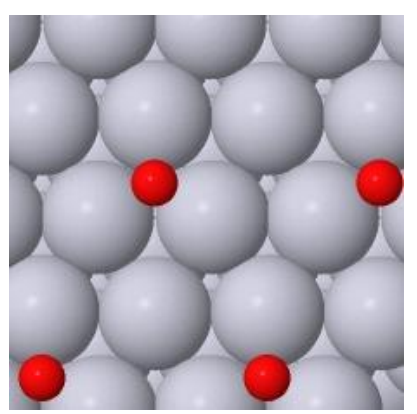

c)

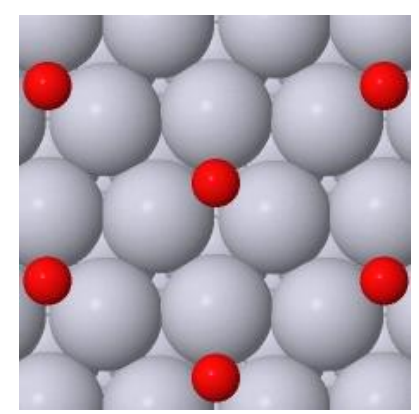

d)

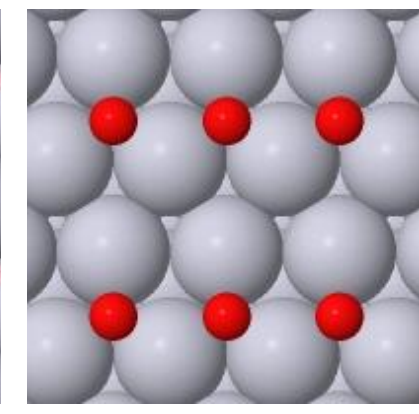

Figure 1 (top panel) Coverages of oxygenated species measured by charge in the $0-1.2 \mathrm{~V}$ potential range on $\mathrm{Pt}(111)$. The rectangles denote the potential stability regions of different coverages. The dashed orange rectangular shows stability region of mixed $\mathrm{OH}-\mathrm{H}_{2} \mathrm{O}$ including VdW interactions. (bottom panel) Illustrations of the $\operatorname{Pt}(111)$ surface with the a) 0.33 ML OH b) 0.25 ML O, c) 0.33 ML O and d) 0.50 ML O coverage.

\section{ORR activity}

We investigate reaction energetics as the surface coverage develops starting from a bare $\operatorname{Pt}(111)$ surface to a surface covered by $0.33 \mathrm{ML} \mathrm{O}$ corresponding to the potential range from $0-1.07 \mathrm{~V}$. The ${ }^{*} \mathrm{O}_{2}$, ${ }^{*} \mathrm{OOH}$ and ${ }^{*} \mathrm{OH}$ intermediates are hydrophilic, meaning they will be stabilized to some 
extent by water molecules at the interface. Therefore, intuitively one could expect the ${ }^{*} \mathrm{O}_{2}$ and ${ }^{*} \mathrm{OOH}$ activation energies to change in the presence of water.

To elucidate the role of solvent, the dissociation of ${ }^{*} \mathrm{O}_{2}$ and ${ }^{*} \mathrm{OOH}$ are modeled with and without water, i.e. for hydrated and dry species, respectively (cf. Figure 2). In the energetically most stable structure, $\mathrm{OH}$ moities point to adsorbed $\mathrm{O}_{2}$ because the number of strong $\mathrm{OH}-\mathrm{H}_{2} \mathrm{O}$ bonds is maximized in such configuration.

a)
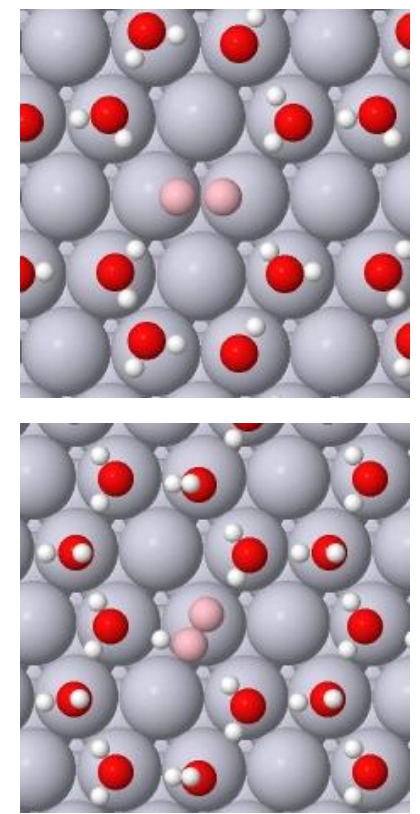

b)
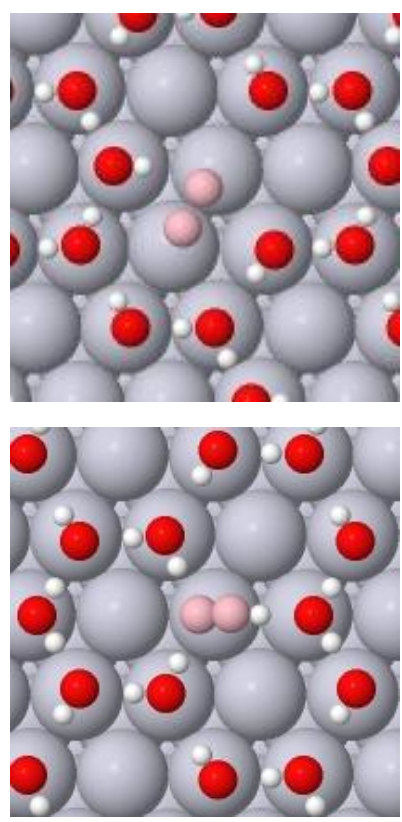

c)
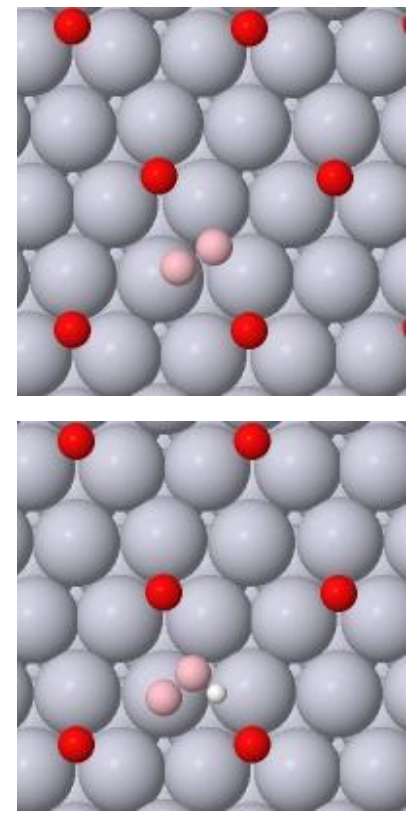

d)
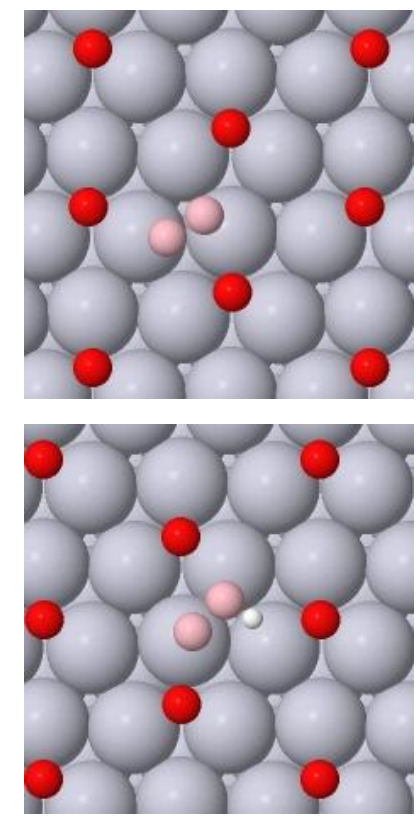

Figure 2 Illustrations of the * $\mathrm{O}_{2}$ and * $\mathrm{OOH}$ adsorption configurations on $\mathrm{Pt}(111)$ at different coverages: a) bare hydrated surface, b) $0.33 \mathrm{ML} \mathrm{OH,} \mathrm{c)} 0.25 \mathrm{ML} \mathrm{O}$ and d) $0.33 \mathrm{ML}$. Oxygen atoms in reaction intermediates are highlighted in pink.

In Table 1, we list the dissociation barriers and reaction free energies for the first electrochemical reduction step $\left({ }^{*} \mathrm{O}_{2}+\mathrm{H}^{+}+\mathrm{e}^{-} \rightarrow{ }^{*} \mathrm{OOH}\right)$ at different coverages. It should be noted that vdW interactions have not been included in the free energy values. A lowest dissociation barrier of 0.52 $\mathrm{eV}$ is obtained on the bare Pt surface, which is in-between $0.30-0.35 \mathrm{eV}$ found experimentally, ${ }^{75,76}$ and $0.8 \mathrm{eV}$ from previous GGA-level DFT studies. ${ }^{51,77} \mathrm{We}$ get the $0.3 \mathrm{eV}$ lower barrier in this study compared to other computational studies because we use a lower $\mathrm{O}_{2}$ surface coverage, i.e. a bigger unit cell. Furthermore, we find the $\mathrm{O}_{2}$ activation energy to be nearly independent of the water solvent, whereby we find a difference of $0.30 \mathrm{eV}$ for the dissociation of dry and hydrated ${ }^{*} \mathrm{OOH}$ (cf. Table 1). In spite of equal $\mathrm{O}_{2}$ activation energies, the dissociation paths for dry and 
hydrated ${ }^{*} \mathrm{O}_{2}$ are not the same. In the former case, the dissociation takes place between a top and a neighboring bridge site, whereas in the latter case, the dissociation path is along the line that connects two Pt top sites (cf. Note 1 in the Electronic Supporting Information). The activation energies are estimated by explicitly modelling the first water layer. We do not expect the inclusion of more water layers to have a sizeable quantitative effect on the dissociation barriers because ${ }^{*} \mathrm{O}_{2}$ and ${ }^{*} \mathrm{OOH}$ in the transition state lie flat on the surface, which minimizes the interaction of dissociated fragments with water in subsequent layers. Even if an effect would exist, it will likely make the dissociation barriers smaller, which would further support the results of this study.

Another challenge is to choose the correct reference for $\mathrm{O}_{2}$. In the conventional volcano picture the free energy difference is measured against the free energy level of $\mathrm{O}_{2}$ in the gas phase, i.e. $\mathrm{O}_{2}(g){ }^{34}$ This might not be the right reference, as $\mathrm{O}_{2}$ binds chemically to the surface a part of useful work that can be converted to electricity is dissipated as heat. However, using chemically adsorbed ${ }^{*} \mathrm{O}_{2}$ as reference gives a much smaller $\left.\left.\Delta G{ }^{*} \mathrm{O}_{2(g)}\right)-\Delta G{ }^{*} \mathrm{OOH}\right)$ free energy difference $(0.53 \mathrm{eV})$ compared to $0.80 \mathrm{eV}$ obtained with $\mathrm{O}_{2}(\mathrm{~g})$. In fact, neither of these approaches are correct because that they do not take into account the pertinent surface coverage at relevant potentials. They are based on calculated adsorption free energies on bare $\operatorname{Pt}(111)$, which is the relevant surface structure in the diffusion controlled regime only. On the other hand, if one takes the HDWL structure that develops close to the potential where ORR become kinetically inhibited, the free energy difference $\Delta G\left(\mathrm{O}_{2}\right)-\Delta G(\mathrm{OOH})=0.77 \mathrm{eV}$ is nearly independent on the choice of reference since $\Delta G\left({ }^{*} O_{2}\right) \approx \Delta G\left(O_{2}(g)\right)$ (cf. Table 1). The $0.77 \mathrm{eV}$ difference coincides closely with the value calculated using the $\mathrm{O}_{2}(\mathrm{~g})$ as reference on the bare $\operatorname{Pt}(111)$ surface, which explains why taking this references gives the correct value of the overpotential. It should be noted that while this conclusion holds for $\operatorname{Pt}(111)$, it might not be necessarily true for other metal surfaces. For the other hydrophilic intermediates, $\mathrm{OH}$ and $\mathrm{OOH}$, we find minor differences for adsorption energies in water and HDWL. The $\Delta G\left({ }^{*} \mathrm{OOH}\right)-\Delta G(\mathrm{OH})$ in the latter is $3.41 \mathrm{eV}$ (see the Method section), which is about $0.1-0.2 \mathrm{eV}$ higher than the average difference computed on a range of bare transition metal and oxide surfaces. ${ }^{69,78}$ The $\left.\Delta G{ }^{*} \mathrm{OOH}\right)-\Delta G\left({ }^{*} \mathrm{OH}\right)$ is a fundamental relation that is believed to be the origin of the overpotential for the ORR. ${ }^{78,79}$ 
Table 1. Average potentials at which the coverage develops (for the bare surface $U=0 \mathrm{~V}$ ), adsorption (at $\mathrm{U}=0 \mathrm{~V}$ ) and dissociation free energies of $\mathrm{O}_{2}$ and $\mathrm{OOH}$, and the reaction free energies for the first electrochemical step at $U=0 \mathrm{~V}$ and average $U$. Potential and free energy units are given in Vs and eVs, respectively.

\begin{tabular}{|cccccccc|}
\hline & $\underline{\mathrm{U}(\mathrm{V})}$ & $\underline{\Delta \mathrm{G}\left(\mathrm{O}_{2}{ }^{*}\right)}$ & $\underline{\Delta \mathrm{G}_{\underline{a}}\left(\mathrm{O}_{2}\right)}$ & $\underline{\Delta \mathrm{G}\left({ }^{*} \mathrm{OOH}\right)}$ & $\underline{\Delta \mathrm{G}_{\underline{a}}(\mathrm{OOH})}$ & \multicolumn{2}{c|}{$\underline{\underline{\mathrm{G}}\left({ }^{*} \mathrm{OOH}-{ }^{*} \mathrm{O}_{2}\right.} \underline{\mathrm{U}}$} \\
Reference U & & 0 & & 0 & & 0 & -0.19 \\
Bare(dry) & 0 & 4.61 & 0.52 & 4.42 & 0.14 & -0.19 & -0.19 \\
Bare(hydrated) & 0 & 4.65 & 0.45 & 4.12 & 0.39 & -0.53 & -0.53 \\
$\mathbf{0 . 3 3}$ ML OH & 0.78 & 4.90 & 0.66 & 4.13 & 0.43 & -0.77 & 0.01 \\
$\mathbf{0 . 2 5}$ ML O & 0.90 & $4.92^{2}$ & 0.63 & 4.33 & 0.64 & -0.59 & 0.31 \\
$\mathbf{0 . 3 3}$ ML O & 1.04 & $4.92^{2}$ & 1.95 & 5.08 & - & 0.16 & 1.20 \\
\hline
\end{tabular}

The dissociation barriers have only been computed for coverages where $\Delta G\left(\mathrm{O}_{2}{ }^{*}\right)-\Delta G\left({ }^{*} \mathrm{OOH}\right)$ > $0.5 \mathrm{eV}$. If the difference is smaller than $0.5 \mathrm{eV}$, an additional thermochemical barrier ontop of a kinetic barrier will render the ${ }^{*} \mathrm{OOH}$ formation unfeasible at relevant potentials. We illustrate this by an example: ${ }^{*} \mathrm{O}_{2}$ reduction to ${ }^{*} \mathrm{OOH}$ at the $0.33 \mathrm{ML} \mathrm{O}$ coverage is uphill in free energy by 0.16 $\mathrm{eV}$ at $\mathrm{U}=0 \mathrm{~V}$. At $0.8 \mathrm{~V}$, the total free energy barrier for $\mathrm{O}_{2}$ reduction becomes $0.96 \mathrm{eV}$, where $0.8 \mathrm{eV}$ comes from the potential dependent difference between the ${ }^{*} \mathrm{O}_{2}$ and ${ }^{*} \mathrm{OOH}$ free energy levels.

The free energy diagrams for the initial electrochemical step at different coverages are shown in Figure 3. As can be seen, the ORR proceeds through the associative mechanism below the 0.25 ML O coverage because the first electrochemical step is downhill in free energy and the *OOH dissociation barrier is lower than the ${ }^{*} \mathrm{O}_{2}$ barrier. ${ }^{3}$ The difference in the ${ }^{*} \mathrm{OOH}$ activation energies on the bare and HDWL surface is $0.04 \mathrm{eV}$, which cannot explain the ORR inhibition at the potentials, where it is observed experimentally. Moreover, the $0.4 \mathrm{eV}$ barrier for ${ }^{*} \mathrm{OOH}$ dissociation is only a moderate barrier, which can sustain current densities at which PEMFCs typically operate. Once the $0.25 \mathrm{ML} \mathrm{O}$ coverage develops the first electrochemical step becomes endergonic. The reaction may continue through the dissociative mechanism because the barrier for

${ }^{2}$ If ${ }^{*} \mathrm{O}_{2}$ is higher in free energy than $\mathrm{O}_{2}(\mathrm{~g})$, the free energy is fixed to the latter value, which is approximately $4.92 \mathrm{eV}$ at standard conditions. The dissociation barriers are calculated from the $\mathrm{O}_{2}(\mathrm{~g})$ free energy level.

${ }^{3}$ we assume charge transfer barriers to be lower than the $\mathrm{O}_{2}$ dissocation barrier. 
$\mathrm{O}_{2}$ dissociation is lower than the sum of the electrochemical barrier for ${ }^{*} \mathrm{O}_{2}$ reduction to ${ }^{*} \mathrm{OOH}$ and the subsequent ${ }^{*} \mathrm{OOH}$ dissociation. The ${ }^{*} \mathrm{O}_{2}$ dissociation barrier of $0.64 \mathrm{eV}$ on the $0.25 \mathrm{ML} \mathrm{O}$ surface is not large enough to explain a sharp activity decrease observed experimentally in the kinetically limited region. This unambiguously leads to the conclusion that factors other than pure surface kinetics govern the reaction rate. We also note that the reaction free energy of the dissociation step should be as low as possible, in order to minimize the waste of electrical energy as argued in refs. 62,80 .

a)


b)

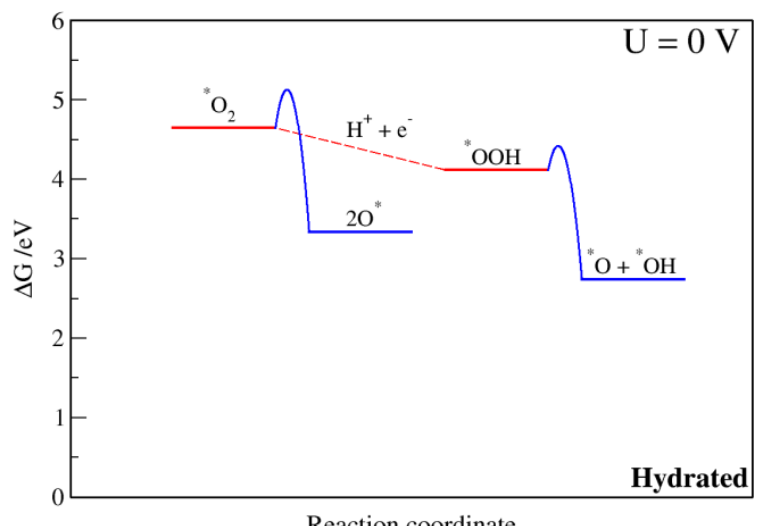

Reaction coordinate

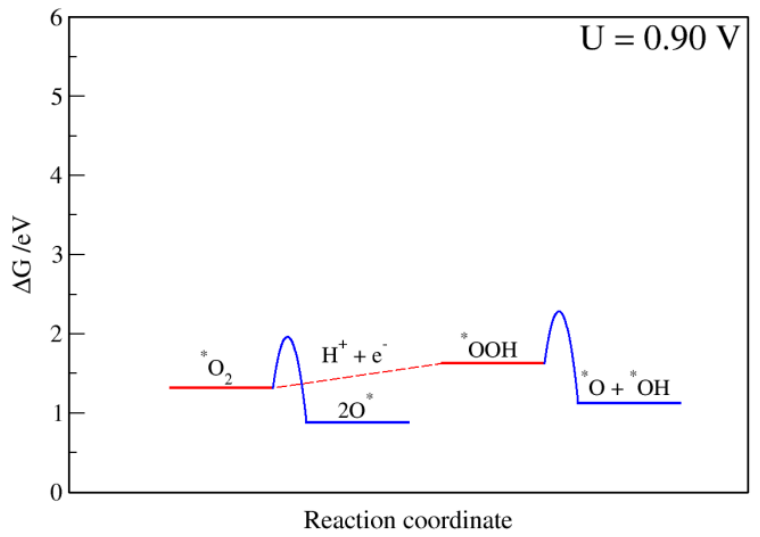

Figure 3 Free energy diagrams for the first electrochemical step for a) dry and b) hydrated intermediates on the bare, c) the $0.33 \mathrm{ML} \mathrm{OH}$ and d) $0.25 \mathrm{ML} \mathrm{O}$ covered Pt(111) slab. Association an dissociation paths are denoted by red and blue lines, respectively.

In the above analysis, we have considered oxygenated species at the surface as ORR intermediates. From an experimental standpoint, $\mathrm{OH}$ is not regarded as an ORR intermediate but a spectator species that consumes empty surface sites needed for $\mathrm{O}_{2}$ adsorption and dissociation. ${ }^{3,81}$ According to this viewpoint, the ORR activity on $\mathrm{Pt}(111)$ and its active alloys $\left(\mathrm{Pt}_{3} \mathrm{Ni}\right.$ and $\left.\mathrm{Pt}_{3} \mathrm{Co}\right)$ is controlled by the $(1-\theta)$ coverage term in the Buttler-Volmer equation. On the other hand, from a theoretical perspective, there is an optimal activity designated by the volcano maximum. For weaker binding energies than those corresponding to maximum activity, the rate is no longer 
controlled by the $\mathrm{OH}$ coverage, but the free energy difference between the ${ }^{*} \mathrm{O}_{2}$ and ${ }^{*} \mathrm{OOH}$ adsorption energies. ${ }^{34,82}$ Using the results in Table 1 we elucidate this point of contention.

So far, we have discussed factors that enter into the rate expression through the exponential term; however, other factors that enter in the rate prefactor are also important. One such factor is the site requirement for reducing oxygen. Namely, oxygen binds to the surface in a bidentate configuration, suggesting that two contiguous free sites are required to activate an oxygen molecule. As there is only one free site in the HDWL layer, one water molecule has to leave the surface to make space for ${ }^{*} \mathrm{O}_{2}$. A usual hypothesis used to calculate the $\mathrm{OH}$ adsorption energy in the HDWL is that water molecules at the interface are in equilibrium with water molelecules in bulk solution. ${ }^{45,56}$ Thus, swapping a surface water molecule with another water molecule from the second layer or bulk solution is, in principle, an equilibrium process. However, the barrier for this process may be high because the water molecules need to break some, if not all, hydrogen bonds at the surface (every water molecule forms two H-bonds as proton donor and one as proton acceptor in HDWL) in order to escape to the $2^{\text {nd }}$ layer, where they can regain enthalpy through hydrogen bonding with water molecules. The differential binding energy of a water molecule in HDWL according to Eq. (5) is $0.42 \mathrm{eV}$. However, removal of water is not the only requirement for $\mathrm{O}_{2}$ to adsorb. Most of the molecules at the interface are water molecules. When a water molecule leaves the surface, the likelihood that another water molecule will fill the empty site is much higher than for an oxygen molecule because of the very poor solubility of $\mathrm{O}_{2}$ in water, $\mathrm{c}\left(\mathrm{O}_{2}\right)=258$ $\mu$ mol for atmospheric oxygen. ${ }^{83}$ At a 1 mol concentration, there are 55 water molecules per $\mathrm{O}_{2}$ meaning that at $\mathrm{c}\left(\mathrm{O}_{2}\right)=258 \mu \mathrm{mol}$, the ratio of water to oxygen molecules is approximately $2.1 * 10^{5}$. Energetically, this corresponds to a value of $0.33 \mathrm{eV}$, assuming a Boltzmann probability distribution. On top of this barrier, there is also a barrier for oxygen diffusion from bulk solution to water at the interface. This barrier is associated with the energy for rearranging water molecules in water layers vicinal to the surface in order to allow $\mathrm{O}_{2}$ to diffuse. The free energy barrier for oxygen adsorption, $\Delta G_{O_{2}}^{H D W L},{ }^{4}$ on the HDWL surface can thus be written as a sum of three terms:

$$
\Delta G_{b_{O_{2}}}^{H D W L}=\Delta G_{H_{2} O}^{H D W L}+\left\{\Delta G\left(O_{2}^{P}\right)+\Delta G\left(O_{2}^{\text {diff }}\right)\right\}
$$

where $\Delta G_{\mathrm{H}_{2} \mathrm{O}}^{\mathrm{O} D L}$ is the differential free energy for water desorption, $\Delta G\left(\mathrm{O}_{2}^{P}\right)$ is the energy that relates to the probability of having oxygen at the right place and time to replace the desorbing

\footnotetext{
${ }^{4}$ The barrier should not be confused with the adsorption free energy of $\mathrm{O}_{2}$ given in Table $\mathbf{1}$.
} 
water molecule and $\Delta G\left(O_{2}^{\text {diff }}\right)$ is the free energy barrier for $\mathrm{O}_{2}$ diffusion through the ice-like water at the interface above the HDWL. The second and the third term are in brackets because in reality they form a single term. The sum of these terms gives a barrier of slightly less than $1.0 \mathrm{eV}$, $\Delta G_{H_{2} \mathrm{O}}^{H D W L}=0.42 \mathrm{eV}, \Delta G\left(O_{2}^{P}\right)=0.33 \mathrm{eV}$ and our conservative estimate for $\Delta G\left(O_{2}^{\text {diff }}\right)$ is $0.1-0.2$ $\mathrm{eV}$. Obtaining the right $\Delta G\left(\mathrm{O}_{2}^{\text {diff }}\right)$ estimate would require a detailed ab initio Molecular Dynamics study, which is beyond the scope of the present study. The much higher barrier than $0.43 \mathrm{eV}$ calculated for ${ }^{*} \mathrm{OOH}$ dissociation supports the hypothesis that the reaction rate is controlled by the reaction prefactor and not the surface kinetics. Thus we conclude that $\mathrm{OH}$ in HDWL has a dual role - it acts both as a reaction intermediate and a spectator species. We estimate however the latter role to control reaction kinetics in the kinetically controlled region.

The above conclusion holds for the HDWL and for water structures with higher $\mathrm{OH}$ coverage, which develop concominantly with the onset of kinetic limitations. At higher potentials the activity reduces sharply with $\mathrm{OH}$ oxidation to $\mathrm{O}$, which also changes the nature of the surface from hydrophilic to hydrophobic. The corresponding $\Delta \mathrm{G}_{\mathrm{b}_{\mathrm{O}_{2}}}^{1 / 4 \mathrm{MLO}}$ to $\Delta \mathrm{G}_{\mathrm{b}_{\mathrm{O}_{2}}}{ }_{\mathrm{HDWL}}$ in Eq. (8) decreases at the very least by the first term on the hydrophobic surface, yielding an energy barrier on the order of $0.5 \mathrm{eV}$, which is lower or similar to the $0.63 \mathrm{eV}$ barrier for ${ }^{*} \mathrm{O}_{2}$ dissociation. According to these values, the reaction would still be able to run although at a reduced rate, which is not in concordance with experiments. To explain why ORR comes to an end on the O covered surface, we make an analogy to $\mathrm{O}_{2}$ adsorption probability in Ultra High Vacuum (UHV) experiments. Namely, under UHV conditions, the $\mathrm{O}_{2}$ sticking coefficient (the probability of a molecule to adsorb) is strongly dependent on the surface oxygen coverage. ${ }^{84,85}$ The initial sticking coefficient on $\operatorname{Pt}(111)$ at $300 \mathrm{~K}$ is $\sim 0.05$ and follows the expected $(1-\theta)^{2}$ dependence,,$^{5}$ on the number of empty sites. Furthermore, it has been shown that a precursor for $\mathrm{O}_{2}$ dissociation in UHV experiments is a chemically adsorbed state, ${ }^{77,85,86}$ meaning that in order for ${ }^{*} \mathrm{O}_{2}$ to dissociate, it first needs to bind chemically to the surface. To a first degree, the sticking coefficient in UHV experiments can be identified with the adsorption probability under ambient conditions. The binding free energy of $\mathrm{O}_{2}$ under the $0.25 \mathrm{ML} \mathrm{O}$ coverage is $5.13 \mathrm{eV},{ }^{6}$ which is $0.21 \mathrm{eV}$ above the free energy level of $\mathrm{O}_{2}$ in gas phase. Using the same rationale as in UHV experiments stipulates that if $\mathrm{O}_{2}$ cannot adsorb to the surface, it will not either be able to dissociate and reduce. This

\footnotetext{
${ }^{5}$ The dependence assumes that two sites are needed to adsorb an $\mathrm{O}_{2}$ molecule.

${ }^{6}$ In Table 1 the adsorption free energy of $\mathrm{O}_{2}$ was fixed to $4.92 \mathrm{eV}$.
} 
explains why ORR is kinetically inhibited by the development of surface oxide. At the other, low potential limit, water does not specifically adsorb on the surface, hence the first two terms in Eq. (8) are zero, and the free energy barrier comes from $\Delta G\left(O_{2}^{\text {diff }}\right)$ alone. The small barrier for $\mathrm{O}_{2}$ diffusion and dissociation, renders the reaction rate under diffusion control.

To conclude, the kinetic limitations on the hydrophilic $\mathrm{OH}-\mathrm{H}_{2} \mathrm{O}$ surface arise as a combination of two main factors that govern the activity, where a smaller contribution comes from 1) activation barriers for the ${ }^{*} \mathrm{OOH}$ dissociation, and a much larger contribution from 2) the probability of $\mathrm{O}_{2}$ to adsorb and replace a surface water molecule. The first and the second factor enter into the rate expression through the exponential and pre-exponetial term, respectively. Both terms are potential dependent, i.e controlled by the oxygenated species coverage, albeit with a much greater coverage dependence of the latter. This result explains why reaction thermochemistry explains well the experimental ORR activity trend on the left leg of the volcano. The same rationale, however, cannot be applied to the right volcano leg, because there, the activity is not controlled by the coverage of surface spectator species but the free energies and activation barriers for ${ }^{*} \mathrm{O}_{2}$ or ${ }^{*} \mathrm{OOH}$ formation and dissociation. ${ }^{87}$ At the $\mathrm{O}$ covered surface (see Figure $3 \mathrm{~d}$ ) that develops at higher potentials, the activity is hampered by the inability of $\mathrm{O}_{2}$ to adsorb. The strong rate dependence on the build-up of oxygenated species coverage implies that the RDS is controlled by the PDS. For ultimately assessing the influence of the RDS and PDS on the ORR rate, it is necessary to make a full microkinetic model that includes all the details of the reaction and the interface, i.e. adsorption and dissociation energies, rate prefactors, charge transfer barriers as well as how these vary with potential.

As a final remark, it would be interesting to investigate whether the same Nernstian process controls the activity of active Pt alloys that terminate with a $\mathrm{Pt}(111)$ layer. In the current theoretical understanding most of these fall on the right volcano leg where $\mathrm{O}_{2}(\mathrm{~g})$ reduction to ${ }^{*} \mathrm{OOH}$ is thought to be the PDS. ${ }^{6,88}$ Adsorption and dissociation free energies are not expected to increase considerably with strain and ligand effect imposed on the surface $\operatorname{Pt}(111)$ layer. Furthermore, we do not expect the $\Delta G_{H D W L}^{a d s}\left(O_{2}\right)$ to change much either; the $\Delta G\left(O_{2}^{P}\right)+\Delta G\left(O_{2}^{\text {diff }}\right)$ sum is weakly dependent on the surface and thus can be assumed constant, whereby $\Delta G_{\mathrm{H}_{2} \mathrm{O}}^{H D L}$ will only slightly be affected by the weaker binding. Therefore, we expect that the coverage of oxygenated species will also govern the ORR activity on the active Pt-alloys, the same way it does 
on $\mathrm{Pt}(111)$. Such interpretation is congruent with the experimental standpoint that the ORR rate on $\mathrm{Pt}$ and its active alloys is controlled by the coverage term in the Buttler-Volmer equation. ${ }^{89}$

\section{Conclusions}

We have provided a new theoretical insight into the ORR mechanism on $\operatorname{Pt}(111)$ by investigating adsorption energies and activation barriers for ${ }^{*} \mathrm{O}_{2} /{ }^{*} \mathrm{OOH}$ formation and dissociation at the coverage that develops in the $0-1.0 \mathrm{~V}$ potential range.

1. On the bare $\operatorname{Pt}(111)$ surface, the water solvation has little effect on the absolute transition state energies for the ${ }^{*} \mathrm{O}_{2}$ and ${ }^{*} \mathrm{OOH}$ dissociation.

2. The ORR proceeds through the associative mechanism. The dissociative mechanism becomes favorable in free energy on the hydrophobic surface, where the reaction is strongly inhibited by the surface species coverage.

3. In the mixed kinetic-diffusion region, the surface is hydrophilic. The RDS is given by a low reaction prefactor, owing to a lengthy process of site exchange between $\mathrm{O}_{2}$ and water molecules co-adsorbed with $\mathrm{OH}$. In the kinetically limited region the surface becomes hydrophobic and the reaction is inhibited by the inability of $\mathrm{O}_{2}$ to adsorb and dissociate on the surface.

4. As the $\mathrm{O}_{2}$ adsorption probability is strongly dependent on the surface coverage, the RDS is governed by the PDS. This result explains why the left leg of the ORR activity volcano provides good activity predictions, without explicitly taking kinetics into account.

\section{Acknowledgments}

We acknowledge the Velux Foundations for support through the VILLUM Center for the Science of Sustainable Fuels and Chemicals (grant number 9455).

\section{Supporting Information}

Supporting Information contains 1 Note:

Note 1: Dissociation paths for dry and hydrated $\mathrm{O}_{2}$. 


\section{References}

(1) DOE Fuel Cell Technologies Program Record, https://www. hydrogen. energy. gov/pdfs/16020_fuel_cell_system_cost_2016.pd. DOE Fuel Cell Technologies Program Record.

(2) Koh, S.; Strasser, P. Electrocatalysis on Bimetallic Surfaces: Modifying Catalytic Reactivity for Oxygen Reduction by Voltammetric Surface Dealloying. J. Am. Chem. Soc. 2007, 129, 12624-12625.

(3) Stamenkovic, V. R.; Fowler, B.; Mun, B. S.; Wang, G. F.; Ross, P. N.; Lucas, C. A.; Markovic, N. M. Improved Oxygen Reduction Activity on Pt3Ni(111) via Increased Surface Site Availability. Science (80-. ). 2007, 315, 493-497.

(4) Wang, C.; van der Vliet, D.; More, K. L.; Zaluzec, N. J.; Peng, S.; Sun, S. H.; Daimon, H.; Wang, G. F.; Greeley, J.; Pearson, J.; et al. Multimetallic Au/FePt3 Nanoparticles as Highly Durable Electrocatalyst. Nano Lett. 2011, 11, 919-926.

(5) Strasser, P.; Koh, S.; Anniyev, T.; Greeley, J.; More, K.; Yu, C. F.; Liu, Z. C.; Kaya, S.; Nordlund, D.; Ogasawara, H.; et al. Lattice-Strain Control of the Activity in Dealloyed Core-Shell Fuel Cell Catalysts. Nat. Chem. 2010, 2, 454-460.

(6) Stephens, I. E. L.; Bondarenko, A. S.; Grønbjerg, U.; Rossmeisl, J.; Chorkendorff, I. Understanding the Electrocatalysis of Oxygen Reduction on Platinum and Its Alloys. Energy Environ. Sci. 2012, 5, 6744-6762.

(7) Stephens, I. E. L.; Bondarenko, A. S.; Pérez-Alonso, F. J.; Calle-Vallejo, F.; Bech, L.; Johansson, T. P.; Jepsen, A. K.; Frydendal, R.; Knudsen, B. P.; Rossmeisl, J.; et al. Tuning the Activity of $\mathrm{Pt}(111)$ for Oxygen Electroreduction by Subsurface Alloying. J. Am. Chem. Soc. 2011, 133, 5485-5491.

(8) Xue, L. Q.; Pang, X. Y.; Wang, G. C. Is the Preadsorbed Sulfur Atom Always Acting as a Poison for the Surface Reaction? J. Phys. Chem. C 2007, 111, 2223-2228.

(9) Sasaki, K.; Naohara, H.; Choi, Y.; Cai, Y.; Chen, W.-F.; Liu, P.; Adzic, R. R. Highly Stable Pt Monolayer on PdAu Nanoparticle Electrocatalysts for the Oxygen Reduction Reaction. Nat. Commun. 2012, 115, 1-9.

(10) Escudero-Escribano, M.; Verdaguer-Casadevall, A.; Malacrida, P.; Grønbjerg, U.; Knudsen, B. P.; Jepsen, A. K.; Rossmeisl, J.; Stephens, I. E. L.; Chorkendorff, I. Pt5Gd as a Highly Active and Stable Catalyst for Oxygen Electroreduction. J. Am. Chem. Soc. 2012, 134, 16476-16479.

(11) Greeley, J.; Stephens, I. E. L.; Bondarenko, A. S.; Johansson, T. P.; Hansen, H. A.; Jaramillo, T. F.; Rossmeisl, J.; Chorkendorff, I.; Nørskov, J. K. Alloys of Platinum and Early Transition Metals as Oxygen Reduction Electrocatalysts. Nat. Chem. 2009, 1, 552556.

(12) Adzic, R. R.; Zhang, J.; Sasaki, K.; Vukmirovic, M. B.; Shao, M.; Wang, J. X.; Nilekar, A. U.; Mavrikakis, M.; Valerio, J. A.; Uribe, F. Platinum Monolayer Fuel Cell Electrocatalysts. Top. Catal. 2007, 46, 249-262.

(13) Tripkovic, V.; Hansen, H. A.; Rossmeisl, J.; Vegge, T. First Principles Investigation of the Activity of Thin Film Pt, Pd and Au Surface Alloys for Oxygen Reduction. Phys. Chem. Chem. Phys. 2015, 17, 11647-11657.

(14) Cui, C.; Gan, L.; Li, H.-H.; Yu, S.-H.; Heggen, M.; Strasser, P. Octahedral PtNi 
Nanoparticle Catalysts: Exceptional Oxygen Reduction Activity by Tuning the Alloy Particle Surface Composition. Nano Lett. 2012, 12, 5885-5889.

(15) Nesselberger, M.; Roefzaad, M.; Faycal Hamou, R.; Ulrich Biedermann, P.; Schweinberger, F. F.; Kunz, S.; Schloegl, K.; Wiberg, G. K. H.; Ashton, S.; Heiz, U.; et al. The Effect of Particle Proximity on the Oxygen Reduction Rate of Size-Selected Platinum Clusters. Nat. Mater. 2013, 12, 919-924.

(16) Shao, M. H.; Peles, A.; Shoemaker, K. Electrocatalysis on Platinum Nanoparticles: Particle Size Effect on Oxygen Reduction Reaction Activity. Nano Lett. 2011, 11, 3714-3719.

(17) Tritsaris, G. A.; Greeley, J.; Rossmeisl, J.; Nørskov, J. K. Atomic-Scale Modeling of Particle Size Effects for the Oxygen Reduction Reaction on Pt. Catal. Letters 2011, 141, 909-913.

(18) Gasteiger, H. A.; Kocha, S. S.; Sompalli, B.; Wagner, F. T. Activity Benchmarks and Requirements for Pt, Pt-Alloy, and Non-Pt Oxygen Reduction Catalysts for PEMFCs. Appl. Catal. B-Environmental 2005, 56, 9-35.

(19) Tripković, V.; Cerri, I.; Bligaard, T.; Rossmeisl, J. The Influence of Particle Shape and Size on the Activity of Platinum Nanoparticles for Oxygen Reduction Reaction: A Density Functional Theory Study. Catal. Letters 2014, 144, 380-388.

(20) Wang, J. X.; Ma, C.; Choi, Y.; Su, D.; Zhu, Y.; Liu, P.; Si, R.; Vukmirovic, M. B.; Zhang, Y.; Adzic, R. R. Kirkendall Effect and Lattice Contraction in Nanocatalysts: A New Strategy to Enhance Sustainable Activity. J. Am. Chem. Soc. 2011, 133, 13551-13557.

(21) Wang, J. X.; Inada, H.; Wu, L. J.; Zhu, Y. M.; Choi, Y. M.; Liu, P.; Zhou, W. P.; Adzic, R. R. Oxygen Reduction on Well-Defined Core-Shell Nanocatalysts: Particle Size, Facet, and Pt Shell Thickness Effects. J. Am. Chem. Soc. 2009, 131, 17298-17302.

(22) Jennings, P. C.; Lysgaard, S.; Hansen, H. A.; Vegge, T. Decoupling Strain and Ligand Effects in Ternary Nanoparticles for Improved ORR Electrocatalysis. Phys. Chem. Chem. Phys. 2016, 18, 24737-24745.

(23) Liu, W.; Rodriguez, P.; Borchardt, L.; Foelske, A.; Yuan, J.; Herrmann, A.-K.; Geiger, D.; Zheng, Z.; Kaskel, S.; Gaponik, N.; et al. Bimetallic Aerogels: High-Performance Electrocatalysts for the Oxygen Reduction Reaction. Angew. Chem. Int. Ed. Engl. 2013, 52, 9849-9852.

(24) Chen, C.; Kang, Y.; Huo, Z.; Zhu, Z.; Huang, W.; Xin, H. L.; Snyder, J. D.; Li, D.; Herron, J. A.; Mavrikakis, M.; et al. Highly Crystalline Multimetallic Nanoframes with ThreeDimensional Electrocatalytic Surfaces. Science 2014, 343, 1339-1343.

(25) Debe, M. K.; Schmoeckel, A. K.; Vernstrom, G. D.; Atanasoski, R. High Voltage Stability of Nanostructured Thin Film Catalysts for PEM Fuel Cells. J. Power Sources 2006, 161, 1002-1011.

(26) Cui, C.-H.; Yu, S.-H. Engineering Interface and Surface of Noble Metal Nanoparticle Nanotubes toward Enhanced Catalytic Activity for Fuel Cell Applications. Acc. Chem. Res. 2013, 46, 1427-1437.

(27) Koenigsmann, C.; Sutter, E.; Chiesa, T. A.; Adzic, R. R.; Wong, S. S. Highly Enhanced Electrocatalytic Oxygen Reduction Performance Observed in Bimetallic Palladium-Based Nanowires Prepared under Ambient, Surfactantless Conditions. Nano Lett. 2012, 12, 20132020. 
(28) Lefevre, M.; Proietti, E.; Jaouen, F.; Dodelet, J. P. Iron-Based Catalysts with Improved Oxygen Reduction Activity in Polymer Electrolyte Fuel Cells. Science (80-. ). 2009, 324, 71-74.

(29) Wu, G.; More, K. L.; Johnston, C. M.; Zelenay, P. High-Performance Electrocatalysts for Oxygen Reduction Derived from Polyaniline, Iron, and Cobalt. Science (80-. ). 2011, 332, $443-447$.

(30) Zheng, Y.; Jiao, Y.; Jaroniec, M.; Jin, Y.; Qiao, S. Z. Nanostructured Metal-Free Electrochemical Catalysts for Highly Efficient Oxygen Reduction. Small 2012, 8, 3550 3566.

(31) Janik, M. J.; Taylor, C. D.; Neurock, M. First-Principles Analysis of the Initial Electroreduction Steps of Oxygen over Pt(111). J. Electrochem. Soc. 2009, 156, B126B135.

(32) Tripkovic, V.; Skúlason, E.; Siahrostami, S.; Nørskov, J. K.; Rossmeisl, J. The Oxygen Reduction Reaction Mechanism on Pt(1 111 ) from Density Functional Theory Calculations. Electrochim. Acta 2010, 55, 7975-7981.

(33) Rossmeisl, J.; Logadottir, A.; Nørskov, J. K. Electrolysis of Water on (Oxidized) Metal Surfaces. Chem. Phys. 2005, 319, 178-184.

(34) Nørskov, J. K.; Rossmeisl, J.; Logadottir, A.; Lindqvist, L.; Kitchin, J. R.; Bligaard, T.; Jonsson, H. Origin of the Overpotential for Oxygen Reduction at a Fuel-Cell Cathode. $J$. Phys. Chem. B 2004, 108, 17886-17892.

(35) Rossmeisl, J.; Qu, Z. W.; Zhu, H.; Kroes, G. J.; Nørskov, J. K. Electrolysis of Water on Oxide Surfaces. J. Electroanal. Chem. 2007, 607, 83-89.

(36) Hansen, H. A.; Viswanathan, V.; Nørskov, J. K. Unifying Kinetic and Thermodynamic Analysis of $2 \mathrm{E}-$ and $4 \mathrm{E}$ - Reduction of Oxygen on Metal Surfaces. J. Phys. Chem. C 2014, 118, 6706-6718.

(37) Jinnouchi, R.; Kodama, K.; Hatanaka, T.; Morimoto, Y. First Principles Based Mean Field Model for Oxygen Reduction Reaction. Phys. Chem. Chem. Phys. 2011, 13, 21070.

(38) Agmon, N. The Grotthuss Mechanism. Chem. Phys. Lett. 1995, 244, 456-462.

(39) Pecina, O.; Schmickler, W. A Model for Electrochemical Proton-Transfer Reactions. Chem. Phys. 1998, 228, 265-277.

(40) Michaelides, A. Density Functional Theory Simulations of Water-metal Interfaces: Waltzing Waters, a Novel 2D Ice Phase, and More. Appl. Phys. A 2006, 85, 415-425.

(41) Rossmeisl, J.; Chan, K.; Ahmed, R.; Tripkovic, V.; Bjorketun, M. E. pH in Atomic Scale Simulations of Electrochemical Interfaces. Phys. Chem. Chem. Phys. 2013, 15, 1032110325.

(42) Karlberg, G. S.; Rossmeisl, J.; Nørskov, J. K. Estimations of Electric Field Effects on the Oxygen Reduction Reaction Based on the Density Functional Theory. Phys. Chem. Chem. Phys. 2007, 9, 5158-5161.

(43) Rossmeisl, J.; Nørskov, J. K.; Taylor, C. D.; Janik, M. J.; Neurock, M. Calculated Phase Diagrams for the Electrochemical Oxidation and Reduction of Water over Pt(111). J. Phys. Chem. B 2006, 110, 21833-21839.

(44) Taylor, C.; Wasileski, S.; Filhol, J.-S.; Neurock, M. First Principles Reaction Modeling of 
the Electrochemical Interface: Consideration and Calculation of a Tunable Surface Potential from Atomic and Electronic Structure. Phys. Rev. B 2006, 73, 165402.

(45) Rossmeisl, J.; Skúlason, E.; Björketun, M. E.; Tripkovic, V.; Nørskov, J. K. Modeling the Electrified Solid-liquid Interface. Chem. Phys. Lett. 2008, 466, 68-71.

(46) Jinnouchi, R.; Anderson, A. Electronic Structure Calculations of Liquid-Solid Interfaces: Combination of Density Functional Theory and Modified Poisson-Boltzmann Theory. Phys. Rev. B 2008, 77, 245417.

(47) Sugino, O.; Hamada, I.; Otani, M.; Morikawa, Y.; Ikeshoji, T.; Okamoto, Y. FirstPrinciples Molecular Dynamics Simulation of Biased Electrode/solution Interface. Surf. Sci. 2007, 601, 5237-5240.

(48) Ford, D. C.; Nilekar, A. U.; Xu, Y.; Mavrikakis, M. Partial and Complete Reduction of O-2 by Hydrogen on Transition Metal Surfaces. Surf. Sci. 2010, 604, 1565-1575.

(49) Xu, Y.; Ruban, A. V; Mavrikakis, M. Adsorption and Dissociation of O2 on Pt-Co and PtFe Alloys. J. Am. Chem. Soc. 2004, 126, 4717-4725.

(50) Miller, D. J.; Öberg, H.; Näslund, L.-Å.; Anniyev, T.; Ogasawara, H.; Pettersson, L. G. M.; Nilsson, A. Low O2 Dissociation Barrier on Pt(111) due to Adsorbate-Adsorbate Interactions. J. Chem. Phys. 2010, 133, 224701.

(51) Nørskov, J. K.; Bligaard, T.; Logadottir, A.; Bahn, S.; Hansen, L. B.; Bollinger, M.; Bengaard, H.; Hammer, B.; Sljivancanin, Z.; Mavrikakis, M.; et al. Universality in Heterogeneous Catalysis. J. Catal. 2002, 209, 275-278.

(52) Liu, S.; White, M. G.; Liu, P. Mechanism of Oxygen Reduction Reaction on Pt(111) in Alkaline Solution: Importance of Chemisorbed Water on Surface. J. Phys. Chem. C 2016, 120, 15288-15298.

(53) Mortensen, J.; Hansen, L.; Jacobsen, K. Real-Space Grid Implementation of the Projector Augmented Wave Method. Phys. Rev. B 2005, 71, 1-11.

(54) Hammer, B.; Hansen, L.; Nørskov, J. Improved Adsorption Energetics within DensityFunctional Theory Using Revised Perdew-Burke-Ernzerhof Functionals. Phys. Rev. B 1999, 59, 7413-7421.

(55) Monkhorst, H. J. Special Points for Brillouin-Zone Integrations. Phys. Rev. B 1976, 13, 5188-5192.

(56) Rossmeisl, J.; Chan, K.; Skúlason, E.; Björketun, M. E.; Tripkovic, V. On the pH Dependence of Electrochemical Proton Transfer Barriers. Catal. Today 2016, 262, 36-40.

(57) Clay, C.; Haq, S.; Hodgson, A. Hydrogen Bonding in Mixed OH+H2O Overlayers on Pt(111). Phys. Rev. Lett. 2004, 92, 46102.

(58) Skulason, E.; Tripkovic, V.; Bjorketun, M. E.; Gudmundsdottir, S.; Karlberg, G.; Rossmeisl, J.; Bligaard, T.; Jonsson, H.; Nørskov, J. K. Modeling the Electrochemical Hydrogen Oxidation and Evolution Reactions on the Basis of Density Functional Theory Calculations. J. Phys. Chem. C 2010, 114, 18182-18197.

(59) Tripkovic, V.; Björketun, M.; Skúlason, E.; Rossmeisl, J. Standard Hydrogen Electrode and Potential of Zero Charge in Density Functional Calculations. Phys. Rev. B 2011, 84, 1-11.

(60) Schnur, S.; Groß, A. Properties of Metal-water Interfaces Studied from First Principles. New J. Phys. 2009, 11, 125003. 
(61) Tang, W.; Lin, H. F.; Kleiman-Shwarsctein, A.; Stucky, G. D.; McFarland, E. W. SizeDependent Activity of Gold Nanoparticles for Oxygen Electroreduction in Alkaline Electrolyte. J. Phys. Chem. C 2008, 112, 10515-10519.

(62) Anderson, A. B.; Jinnouchi, R.; Uddin, J. Effective Reversible Potentials and Onset Potentials for $\mathrm{O}_{2}$ Electroreduction on Transition Metal Electrodes: Theoretical Analysis. $J$. Phys. Chem. C 2013, 117, 41-48.

(63) Gasteiger, H. A.; Markovic, N. M.; Ross, P. N. Bromide Adsorption on Pt(111):? Adsorption Isotherm and Electrosorption Valency Deduced from RRD Pt(111) E Measurements. Langmuir 1996, 12, 1414-1418.

(64) Michaelides, A.; Alavi, A.; King, D. Insight into H2O-Ice Adsorption and Dissociation on Metal Surfaces from First-Principles Simulations. Phys. Rev. B 2004, 69, 113404.

(65) Schiros, T.; Naslund, L. A.; Andersson, K.; Gyllenpalm, J.; Karlberg, G. S.; Odelius, M.; Ogasawara, H.; Pettersson, L. G. M.; Nilsson, A. Structure and Bonding of the WaterHydroxyl Mixed Phase on Pt(111). J. Phys. Chem. C 2007, 111, 15003-15012.

(66) Bondarenko, A. S.; Stephens, I. E. L.; Hansen, H. A.; Pérez-Alonso, F. J.; Tripkovic, V.; Johansson, T. P.; Rossmeisl, J.; Nørskov, J. K.; Chorkendorff, I. The Pt(111)/electrolyte Interface under Oxygen Reduction Reaction Conditions: An Electrochemical Impedance Spectroscopy Study. Langmuir Acs J. Surfaces Colloids 2011, 27, 2058-2066.

(67) Rossmeisl, J.; Karlberg, G. S.; Jaramillo, T.; Nørskov, J. K. Steady State Oxygen Reduction and Cyclic Voltammetry. Faraday Discuss. 2008, 140, 337-346.

(68) Karp, E. M.; Campbell, C. T.; Studt, F.; Abild-Pedersen, F.; Nørskov, J. K. Energetics of Oxygen Adatoms, Hydroxyl Species and Water Dissociation on Pt(111). J. Phys. Chem. C 2012, 116, 25772-25776.

(69) Christensen, R.; Hansen, H. A.; Dickens, C. F.; N?rskov, J. K.; Vegge, T. Functional Independent Scaling Relation for ORR/OER Catalysts. J. Phys. Chem. C 2016, 120, 24910 24916.

(70) Bellarosa, L.; García-Muelas, R.; Revilla-López, G.; López, N. Diversity at the WaterMetal Interface: Metal, Water Thickness, and Confinement Effects. ACS Cent. Sci. 2016, 2, 109-116.

(71) Nie, S.; Feibelman, P. J.; Bartelt, N. C.; Thürmer, K. Pentagons and Heptagons in the First Water Layer on Pt(111). Phys. Rev. Lett. 2010, 105, 26102.

(72) Hansen, M. H.; Nilsson, A.; Rossmeisl, J. Modelling pH and Potential in Dynamic Structures of the water/Pt(111) Interface on the Atomic Scale. Phys. Chem. Chem. Phys. 2017, 19, 23505-23514.

(73) Zeng, Z.; Greeley, J. Characterization of Oxygenated Species at water/Pt(111) Interfaces from DFT Energetics and XPS Simulations. Nano Energy 2016, 29, 369-377.

(74) Carrasco, J.; Hodgson, A.; Michaelides, A. A Molecular Perspective of Water at Metal Interfaces. Nat. Mater. 2012, 11, 667-674.

(75) Nolan, P. D.; Lutz, B. R.; Tanaka, P. L.; Davis, J. E.; Mullins, C. B. Molecularly Chemisorbed Intermediates to Oxygen Adsorption on Pt(111): A Molecular Beam and Electron Energy-Loss Spectroscopy Study. J. Chem. Phys. 1999, 111, 3696.

(76) Stipe, B.; Rezaei, M.; Ho, W.; Gao, S.; Persson, M.; Lundqvist, B. Single-Molecule Dissociation by Tunneling Electrons. Phys. Rev. Lett. 1997, 78, 4410-4413. 
(77) Eichler, A.; Mittendorfer, F.; Hafner, J. Precursor-Mediated Adsorption of Oxygen on the (111) Surfaces of Platinum-Group Metals. Phys. Rev. B 2000, 62, 4744-4755.

(78) Man, I. C.; Su, H.-Y.; Calle-Vallejo, F.; Hansen, H. A.; Martínez, J. I.; Inoglu, N. G.; Kitchin, J.; Jaramillo, T. F.; Nørskov, J. K.; Rossmeisl, J. Universality in Oxygen Evolution Electrocatalysis on Oxide Surfaces. ChemCatChem 2011, 3, 1159-1165.

(79) Koper, M. T. M. Theory of Multiple Proton-Electron Transfer Reactions and Its Implications for Electrocatalysis. Chem. Sci. 2013, 4, 2710-2723.

(80) Tian, F.; Anderson, A. B. Effective Reversible Potential, Energy Loss, and Overpotential on Platinum Fuel Cell Cathodes. J. Phys. Chem. C 2011, 115, 4076-4088.

(81) Markovic, N.; Gasteiger, H.; Ross, P. N. Kinetics of Oxygen Reduction on Pt(hkl) Electrodes: Implications for the Crystallite Size Effect with Supported Pt Electrocatalysts. J. Electrochem. Soc. 1997, 144, 1591-1597.

(82) Tripkovic, V. Thermodynamic Assessment of the Oxygen Reduction Activity in Aqueous Solutions. Phys. Chem. Chem. Phys. 2017.

(83) The Engineering Toolbox. http://www.engineeringtoolbox.com/oxygen-solubility-waterd_841.html.

(84) Winkler, A.; Guo, X.; Siddiqui, H. R.; Hagans, P. L.; Yates, J. T. Kinetics and Energetics of Oxygen Adsorption on Pt(111) and Pt(112)- A Comparison of Flat and Stepped Surfaces. Surf. Sci. 1988, 201, 419-443.

(85) Campbell, C. T.; Ertl, G.; Kuipers, H.; Segner, J. A Molecular Beam Study of the Adsorption and Desorption of Oxygen from a Pt(111) Surface. Surf. Sci. 1981, 107, 220 236.

(86) Luntz, A. C.; Williams, M. D.; Bethune, D. S. The Sticking of O2 on a Pt(111) Surface. J. Chem. Phys. 1988, 89, 4381.

(87) Hansen, H. A.; Viswanathan, V.; Nørskov, J. K. Unifying Kinetic and Thermodynamic Analysis of $2 \mathrm{E}^{-}$and $4 \mathrm{E}^{-}$Reduction of Oxygen on Metal Surfaces. J. Phys. Chem. C 2014, 118, 6706-6718.

(88) Stamenkovic, V.; Mun, B. S.; Mayrhofer, K. J. J.; Ross, P. N.; Markovic, N. M.; Rossmeisl, J.; Greeley, J.; Nørskov, J. K. Changing the Activity of Electrocatalysts for Oxygen Reduction by Tuning the Surface Electronic Structure. Angew. Chemie-International Ed. 2006, 45, 2897-2901.

(89) Stamenkovic, V. R.; Mun, B. S.; Arenz, M.; Mayrhofer, K. J. J.; Lucas, C. A.; Wang, G. F.; Ross, P. N.; Markovic, N. M. Trends in Electrocatalysis on Extended and Nanoscale PtBimetallic Alloy Surfaces. Nat. Mater. 2007, 6, 241-247. 
TOC Graphic

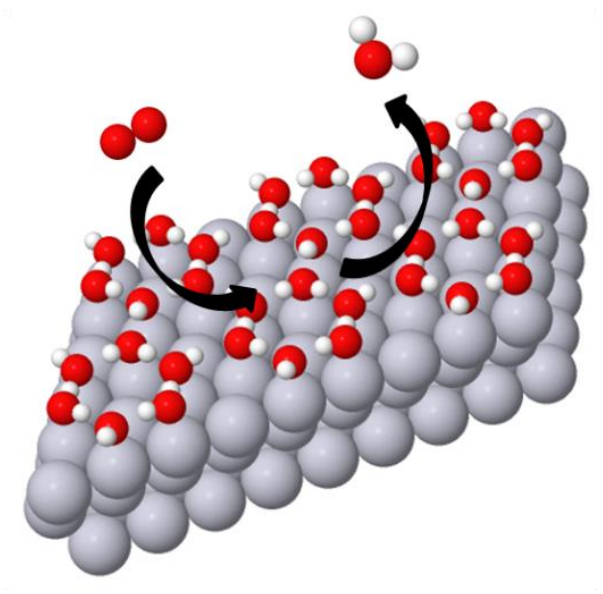

